in response to experience. Edelman explains how these devices can learn to recognize patterns and navigate new environments. This is intriguing, but it is rather difficult to assess its significance in the absence of any comparison with other learning-based robotics research.

This lack of scientific comparisons is a striking feature of the book. A naive reader could easily form the impression that Edelman and his associates are the only people trying to use scientific information to cast light on the human mind. Not that the book lacks references: it is full of brief digests of philosophical and cultural figures, such as Wilhelm Dilthey, Ludwig Wittgenstein, Isaiah Berlin, Richard Rorty and many more. It is impressive that Edelman should have read their work, but I couldn't help wondering who his own book was written for. Is there really a readership for potted cultural history written by senior scientists? In any case, this is not a book for those who want to know how brain science relates to epistemology.

David Papineau is professor of the philosophy of science, King's College London, London WC2R 2SL, UK. He is the author of Thinking About Consciousness (Oxford University Press, 2002).
FILM

\section{Dark days ahead}

\section{Sunshine}

directed by Danny Boyle, written by

Alex Garland

Twentieth Century Fox. Worldwide release from 6 April 2007

\section{Richard Webb}

"Our Sun is dying," intones a laconic voiceover at the start of the film Sunshine. Why, in the year 2057, Earth's star is failing is unspecified. Astrophysical orthodoxy would demand that life on Earth is extinguished by the Sun's red-giant phase long before its light fades away - and that only in billions of years' time. But as Brian Cox, a researcher at the particlephysics laboratory CERN who acted as scientific consultant to the film, was at pains to point out in the pre-release publicity, there is still a lot we don't know about the Universe. The cosmos, like the cinema, is a medium of infinite surprises.

Not that Sunshine, at least in its basic scenario, is surprising at all. This is cinematic déjà vu: with humanity's survival threatened, a group of brave, bright young things must take up arms for all our sakes. The eightman crew of the spaceship Icarus II has been charged with restarting the Sun. They have to drop a nuclear payload - fissile material amounting to the mass of Manhattan - into its core. A first attempt, Icarus I, has failed, with all contact having been lost seven years before.

Early enough in this second, last-gasp mission, a law of cinema as ineluctable as the law of gravity kicks in: what goes up never looks like coming down. Icarus II's calamities begin as it prepares for the slingshot round Mercury that will propel it into the Sun's corona: it picks up a distress signal from Icarus I. Diverting course towards their lost predecessor engenders a chain of events that puts both mission and crew in mortal danger.

But like Icarus II, the film manages to diverge from its preordained trajectory. Despite its big-budget look and feel, this is a (relatively) cheap-and-cheerful British production, which frees it from some of the more egregious demands of Hollywood schmaltz. In particular, its commitment to a happy ending is equivocal; each setback to the mission also demonstrably reduces the crew's own chances of survival. "There will be no ticker-tape parade," says Mace, the hard-boiled engineer, with bitter resignation as a particularly cruel sideswipe of fate blows out most of the ship's oxygen. That fatalistic undercurrent makes for an interesting study of human interactions in a - literally and metaphorically - pressurized environment.

Science is handled pleasingly well in Sunshine. Scientific vocabulary is not flung about with the gay, context-free abandon that is traditional in such circumstances. Before shooting the film, Cillian Murphy, who plays physicist Capa, guardian of Icarus II's nuclear payload, visited CERN to observe real physicists in their natural habitat. The gratifying (if somewhat surprising) result is a scientist on the silver screen who seems manifestly sane. It is true that when I worked at CERN, none of my physicist colleagues there had quite such rippling biceps, nor did they pout in the face of adversity quite so provocatively as Capa. But this much can be forgiven in the exercise of creative licence.

As Sunshine and Icarus II hurtle ever faster to their destination, the plot's twists lean ever more towards the demands of cinema than those of solid science. But you don't go to a blockbuster film to be entertained by two hours of fastidiously researched plausibility: wall-towall action, searing special effects, a messianic score and fine acting are generally more than adequate compensation. Sunshine has these in abundance.

And yet this film has only one true star: the Sun's yellow-orange plasma, a constant, hypnotic backdrop shown off to full advantage in an early scene as the ship's crew watches the tiny black silhouette of Mercury transit across its shimmering face. At a time when we are ever more concerned with Earthbound threats to humanity's survival, such images are an aweinspiring tribute to a power of nature that will, in time, be the death of Earth. Five billion years' hence, however, we probably shan't be around to rage against the dying of the light.

Richard Webb is Nature's physics News \& Views editor.



